\title{
Swarnnadwipa Abad XIII-XIV Masehi Penggunaan Atas Sumber Emas di Hulu Batanghari (Sumatra Barat)
}

\section{Bambang Budi Utomo}

Keywords: inscription, Ancient Melayu, Batanghari River, Adityawarman

\section{How to Cite:}

Utomo, B. B. Swarnnadwipa Abad XIII-XIV Masehi Penggunaan Atas Sumber Emas di Hulu Batanghari (Sumatra Barat). Berkala Arkeologi, 14(2), 221-226. https://doi.org/10.30883/jba.v14i2.728
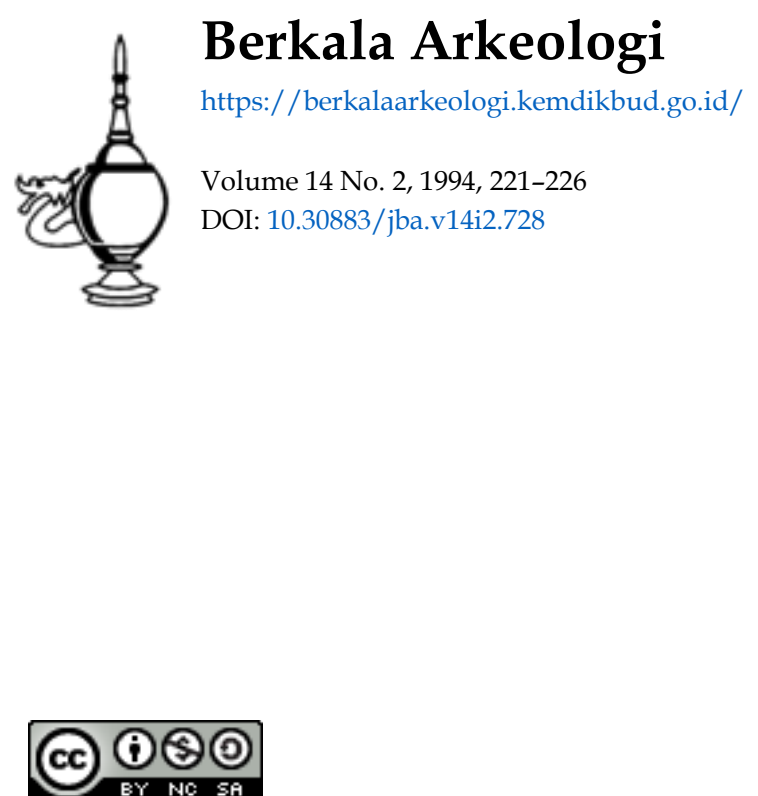

This work is licensed under a Creative Commons Attribution-NonCommercial-ShareAlike 4.0 International License. 


\title{
SWARNNADWIPA ABAD XIII - XIV MASEHI PENGGUNAAN ATAS SUMBER EMAS DI HULU BATANGHARI (SUMATRA BARAT)
}

\author{
Bambang Budi Utomo \\ (Pusat Penelitian Arkeologi Nasional)
}

\section{Pengantar}

Beberapa waktu yang lampau, pada tanggal 7-8 Desember 1992 di Jambi telah diselenggarakan Seminar Sejarah Melayu Kuna. Kemudian pada tanggal 26 Juni 1993 di Padang telah diselenggaran Diskusi Arkeologi yang membicarakan tokoh Adityawarman. Kedua peristiwa ini bertujuan mengangkat kembali nama Kerajaan Melayu yang telah lebih dari 14 abad tenggelam da lam hiruk- pikuknya lakon sejarah Nusantara

Dalam Seminar Sejarah Melayu Kuna terungkap lokasi kerajaan Melayu ada di daerah Sungai Batanghari, mulai dari daerah hilir di wilayah Provinsi Jambi hingga daerah hulu di wilayah Provinsi Sumatra Barat. Bukti arkeologis menunjukkan ada pergeseran pusat kerajaan mulai dar arah hilir ke arah hulu Batanghari (Bambang Bud Utomo,1992:183-84). Demikian juga bukti prasasti menunjukkan bahwa prasasti-prasasti Melayu yang lebih muda ditemukan di derah hulu Batangharı, di Sumatra Barat (Hasan Dj, 1992:50-80)

Jika dilihat dari pandangan geografis, daerah hilir Sungai Batanghari lebih menguntungkan jika dibandingkan dengan daerah hulu. Di wilayah pedalaman Sumatra Barat, jalan keluar menuju Selat Malaka adalah Sungai Indragiri dan Sungai Kampar Kiri. Kedua sungai ini bermata-air di wilayah Pagarruyung. Tentunya tidak memungkinkan untuk pelayaran sungai. Namun pada pertengahan abad ke-14 Masehi pusat Kerajaan Melayu mencapai puncak kejayaannya? Gejala apakah yang memacu perkembangan kerajaan inı. Untuk menjawab peitanyaan ini saya akan mengemukakarı pandangan dari sumberdaya alam yang tersedia di wilayah Provinsı Sumatra Barat.

\section{Perpindahan Pusat Pemerintahan}

Wilayah Kerajaan Melayu Kuno secara geografis terletak di sekitar aliran Sungai Batangharı yang meliputi Provinsi Jambi dan Provinsi Sumatra Barat. Di beberapa tempat, di tepian Sungai Batanghari banyak ditemukan situs arkeologi mulai dari daerah hilir (di wilayah Provinsi Jambi) hingga daerah hulu (di wilayah Provinsi Sumatra Barat Situs-situs itu antara lain Muara Sabak Koto Kandis, Situs di daerah pertemuan Sungai Batangharidan Sungai Kumpeh (Ujung Plancu, Suakkandis, dan Sematang Pundung), Muara Jambi, dan Solok Sipın (Jambi) di wilayah Provinsi Jambi; dan situs Rambahan. Pulau Sawah
Siguntur, dan Padangroco di wilayah Provinsı Sumatra Barat.

Berdasarkan identıfikasi unsur pertanggalan yang diperoleh dari paleografi tulisan-tulisan singkat pada lempeng emas di Candi Gumpung (Boechari,1984:9; 1985:237-38), tulisan singkat pada batu pipisan dari Koto Kandis (Bambang Budi Utomo, 1990:148), tulisan singkat pada arca Buddha dari Solok Sipin (Boekhori, 1979:28), dan pecahan-pecahan keramik (Bambang Budi Utomo 1990:148) menunjukkan pertanggalan abad ke13-14 Masehi (Bambang Budi Utomo, 1992)

Pertanggalan situs tersebut menunjukkan di Daerah Batanghari pada masa lampau terjadi pergeseran pemukiman. Pemukiman yang tua berlokasi di daerah hilir Batanghari, sedangkan pemukiman yang muda berlokası di daerah hulu Batanghari di wilayah Sumatra Barat. Dalam sejarah Jambi (Batanghari) wilayah ini pernah terdapat dua kerajaan yang berpengaruh di wilayah sebelah barat Nusantara. Kedua kerajaan itu adalah Malayu dan Sriwijaya yang tumbuh dan berkembang pada waktu yang bersamaan. Darı berita cina yang ditulis oleh l-tsing disebutkan bahwa suatu saat (sekitar tahun 670-an) Malayu pernah menjadi bagian dari Sriwijaya (Groenewwitd, 1960) Setelah Sriwijaya melemah, Malayu kemudian merdeka kembali. Berdasarkan berita Cina itu, Hasan DJafar membagi melayu dalam tiga fase (Hasan Djafar, 1992:77), yaitu

Fase 1: Fase awal, sekıtar pertengahan abad ke-7 Masehi,

Fase II . Fase pendudukan Sriwijaya, sekitar tahun 680 sampal sekitar pertengahan abad ke-11 Masehı

Fase III Fase Akhir, sekitar pertengahan abad ke-11 sampai sekitar akhir abad ke-14 Masehi.

Ketiga fase teısebut mengacu pada perjalanan sejarah Kerajaan Malayu Kuno, tetapı tıdak menjelaskan lokasi pusat pemerıntahannya. Sebagaimana telah dikemukakan bahwa lokası geografis Melayu ada di daerah Batanghari. Beberapa pakar berpendapat bahwa Pusat Melayu Kuno, pada fase awal berlokasi di sekitar Kota Jam. bı sekarang (Slamet Mulyana,1981:30-42; Irfan. 1983:94-102). Pendapat ini didasarkan asums bahwa pusat kerajaan adalah juga merupakan Pelabuhan Malayu. Pelabuhan Malayu yang lokasinya di tepi sungai Batanghari sangat baik untuk pelabuhan sungai. Sungai Batanghari yang 
panjangnya $\pm 800 \mathrm{~km}$, lebamya $\pm 500 \mathrm{~m}$ dan kedalamannya lebih dari $5 \mathrm{~m}$ cukup baik untuk pelayaran sungai. Panjang sungai yang dapat dilayarı perahu atau kapal besar adalah $\pm 600 \mathrm{~km}$. Selebihnya hanya dapat dilayari perahu kecil.

Sedikit data tertulis mengenai fase awal Melayu yang sampai kepada kita. Nama Malayu untuk pertama kalinya disebut dalam kronik Shin Tang-shu. Dalam kronik itu disebutkan bahwa duta Mokayou datang ke istana kaisar Cina pada bulan 644dan 645 Masehi (Pelliot 1904:324,344). Selanjutnya nama Melayu tercantum dalam catatan harian l-tsing tinggal selama dua bulan sebelum melanjutkan pelayaran ke Chieh-cha dan menuju Nalanda (India)(Wheatly, 1961:41.42) Data inı memberikan informasi pada waktu itu $\mathrm{Ma}$ layu masih merupakan negara yang merdeka yang mengirimkan duta ke Negeri Cina.

Fase kependudukan Srimijaya data tertulisnya diperoleh dari catzotan harian l-tsing dan prasast Karangberahi. I-tsing menyebutkan bahwa sekembalinya dari Nalanda, pada tahun $685 \mathrm{M}$ ia singgah di Moło-yeu yang sekarang menjadi Fa sho do. Prasasti Karangberahs yang ditemukan ditepı Sungai Merangin, cabang Sungai Batanghari; menyebutkan tentang persumpahan bagi yang tidak mau tunduk kepada Kadatuan Sriwijaya. Kedua data ini menginformasikan kepada kita bahwa pada waktu itu Malayu telah ditaklukkan oleh Srimijaya. Masa Pendudukan Sriwijaya bertangsung cukup lama. Nama Malayu tidak lagi terdengar sampai abad ke-13 Masehi

Masa pendudukan oleh Sriwijaya agaknya berlangsung cukup lama, mulai dari abad ke-7 sampai abad ke-11 M. Tetapi selama itu, ada juga masa di mana Sriwijaya agak lengah. Kesempatan itu digunakan untuk mengirimkan duta ke Cina. Berdasantan catatan Cina, Mo-lo-yeu mengirimkan utusan ke Cina pada tahun 853 dan 871 M Notters, 1970:41-42). Namun tindakan ini segera diketahul Sriwijaya. Oleh sebab itulah, maka pada tahun 905 M Raja Sriwijaya mengirimkan utusan ke Cina dan menegaskan bahwa duta yang datang pada tahun 853 dan $871 \mathrm{M}$ adalah "pernimpin dan Chan-pi" (Groeneveldt, 1960.64).

Malayu mulai melepas diri dari Srivijaya pada sekitar abad ke-11 M. Sebuah prasosti yang ditemukan di Srilanka menyebutkan bahwa pada jaman pemerintahan Vijayabahu di Srilanka (1055-1100 M), pangeran Suryanarayana dari Malayapura berhasil memegang tampuk pemerintahan di Suwamapura (Wolters, 1970:92-93). Kronik Cina, Ling-wai-tai-ta, menyebutkan bahwa pada tahun 1079, 1082 dan 1088, negeri Chan-pi di San-fo-tsi mengirimkan utusan ke negeri Cina (Hith \& Rock hill 1911: 66).

Kronik Istana Kerajaan Pagan dari abad ke12 M menyebutkan adanya hubungan dengan kerajaan Malayu. Raja Pagan mengirim pendeta Buddha untuk menterjemahkan naskah-naskah agama Buddha atas perintah raja Malayu. Pendeta ini kemudian mengawini putri raja dan tinggal di Istana Malayu(Adhyatman, 1990 103)

Setelah lepas dari Sriwijaya, kerajaan Mala. yu Kuno tetap dipertitungkan sebagaı sebuah kerajaan yang memegang peranan penting. Pada waktu Malayu sudah merdeka, Kerajaan Singhasari di Jawa sedang berselisih dengan Mongol di daratan Cina. Bahkan Singhasari sedang meng. hadapi ancaman penyerbuan tertara Mongol. Un tuk tidak memperbanyak musuh, Singhasari de. ngan rajanya Krtanagara berkeinginan menjalin persahabotan dengan Malayu. Besomya perhats an Krtanagara kepada Kerajaan Malayu mem buktikan bahwa pada abad ke-13 M. Kerajaan Malayu merupakan negara utama di Sumatra Untuk itulah maké pada tahun 1275 Singhasarı mengadakan ekspedisi pemalayu.

Berita tertulis penting mengenai keberadaan lokasi pusat Malayu di hulu Batanghari diperoleh dari dua buah prasasti, yaitu Prasasti Dharmma. sraya yang berangka tahun $1347 \mathrm{M}$. Selain itu ter dapat prasasti-prasasti lain yang ditemukan di daerah pedalaman Sumatra Barat (Pagarruyung dan Batusangkar).

Prasasti Dharmmasraya menyebutkan pada tahun $1286 \mathrm{M}$ sebuah arca Amoghapasa, keempat-belas pengiringnya, dan septaratna dibawa dari Bhumi Jawa ke Swamnabhumi untuk ditempatkan di Dharmmasraya sebagai punya Sn Wiswarupakumara. Sri Maharajadhiraja Krtanagara memerintahkan Raknan Mahamantri Dyah Adwayabrahma, Rakryan Sirikan Dyah Sugatabrahma, Samgat Payanan Han Dipangkaradasa, dan Rakryan Dmun Pu Wira untuk mengiringkan arca tersebut Seluruh rakyat malayu dari keempat kasta bersuka-cita, terutama rajanya, Srimat Tribhuwana-raja Mauli Warmmadewa (Hasan DJ, 1992:56-8).

Isi prasasti tersebut memberikan informasi raja Malayu, Srimat Tribhumanaraja Mauliwarmmadewa berkedudukan di Dharmmasraya. Lokasi Dharmmasraya terdapat di sekitar daerah Sawah-lunto-sijunjung di kampung Rambahan. tempat prasasti ditemukan sekitar tahu 1980-an (Krom,1912:48). Di sekitar daerah ini ditemukan juga beberapa kelompok bangunan candi yang terdapat di beberapa lokasi, yaitu Padangroco Pulau Sawah, Siguntur, dan Rambahan (Bambang Budi Utomo, 1992).

\footnotetext{
1 Kitab Pararaton menyeducen "Setetah musuh ini ma

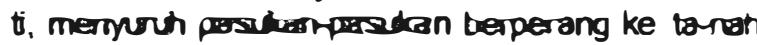
Malayur (Pitono, 1965:37). Itutah sebabmya banyzk para sarjana berpentapal balwwo elspedisi pamalayu berarti pendection atas matoyu
} 
Ekspedisi Pamalayu oien Deberapa sanana citatsinkan sebagai penductukan atau penguasaan Malayu. Namun berdasarkan isi prasasti Dharmmasraya petunjuk tersebut tidak tampak, seperti tercantum dalam kalimat "Seluruh rakyat Malayu deri keempet kaste bersuke cita, tenuto me rajanya Srimet Tribhwenaraja Mauriwarmma dewa" Arca Amoghapasa yang dikirimkan olen Krtanagara ditemukan kembali di Padangroco, letaknya sokior $4 \mathrm{~km}$ ke arah hilir dari Rambahan. Meskipun ditemukan terpisah, namun berdasarkan isi prasest Dharmmasraya yang dipahatkan pada bagian lapik arca, arca Amoghapasa yang ditemukan di Padangroco ternyato merupakan Pasangannya.

Arca Amoghapasa yang ditemukan di Padangroco sekitar tahun 1800-an (Krom, 1912:48) member pebunjuk batwro pada tahun 1347 yang berkuasa di daerah itu (Malayu) adalah Sri Maharaja Adityawarman upacara yang bercorak tantrk, pendirian sebuah arca Buddha, dan pemujaan kepada Jina. Informasi yang terdiri dari 27 baris itu dipahatkan di bogian belakang arca Amoghapasa yang dikirim oleh Ktanagara. Berdasarkan isi prasast ini para sajjana beranggapan balmwa pada tahun 1347 merupakan tahun awal pemenntahan Adityawarman di Malayu

Prasasti bin yang Jełas-jelas menyebutkan perpindahan pusat pemenintahan adaiah prasast Gudam. Berdasarkan infomasi dari parasasti ini, de Casparis berkesimpulan bahwa yang memindahkan pusat kekuasaan ke daerah Batusangkar adalah Akarendrawarman, raja Malay pendahuIu Adityoworman (1989 dan 1992). Pada sekitar tahun 134a-an di daerah Batusangkar dan Pagarruyng memeintah seorang raja yang bemama Adifomaman. Pada prasasti-prasasti yang ditemukan di daerah tersebut misainya prasasti $\mathrm{Ka}$ burajo I menyebutken bahwa Acityowarman memerintah di Kanakargedinindra (=raja pulau emas)(Kem,1917:219). Pada tahun 1347, ber-

\footnotetext{
- Nama Adityoworman dikeng uga datam Prasastj Arca Marusiri dan tahun 1344 Masehi yang ditemukan d halaman Cand Jago (Makang. Jawo Timer). Isimya menyetuban penemptan sebugh arca moniusri d tempat penshomian Jina oleh Adityawarmon den perdanguran sebuen cand Budcha dengen tyian untik mernuliakan orang tisa dan kerabotiyo. Dengan dikerabina nema Adtyomarman di Jawa dan Sumo. tra. dapat diduga barwa tokon in menpeicen rokoh penting pada wakds itu Untuk semestroro tokon adalah secrang tangsaman jawa-Malayu yarng pada mu lanyo doesarkan a Jawa, Husesrya di lingkergan keraton Majapahit Pada suetus saat Adtyawaman dapat dengan mudah mencudvo tanta Matoys. Hal in dsebabkan karena la iga bukan olang sembarang an Setidak-tidatoma ia odalah seorang bangovran matays Mingkon penempatan Adtyawaman di malay. adalah salah satu postik Majapanit utue mena-
}

dasarkan IS prasasti Amoghapasa la mengangkat dirinya menijadi seorang Maharajadhuzja dengan gelar Udayadityawarman atau Adityawarmodaya Pratapaprakramarajendra Mauliwarmmadewa

Berdasarkan prasasti dan pertanggalan situs di daerah Batanghari, Kerajaan Malayu sekurangkurangnya telah mengalami tiga kali pemindathan pusat pemerintahan. Pusatrya yang pertama berlokasi di sekitar kota Jambi sekarang, pusat yang kedua di daerah Padangroco, dan pusat yang ketiga di daerah Pagarruyung. Para sanana beranggapan bahwa pemindahan pusat pemerintahan ini disebabkan karena ancaman dari musuh, terutama yang datang dari Jawa malui Sungai Batanghari. De Casparis menduga bahwa Malayu pada masa akhir mendapat ancaman dan kerajaan yang beroorak Islam di Samudera Pasai (1992). Unsur ancaman dari negara tetangga memang ada, tetapi datam hal ini saya lebih condong untuk menyatakan batrwa alasan pemindahan pusat pemerintahan adalah untuk penguasaan sumber emas yang banyak terdapat di daerah pedalaman. Oisomping itu, secara geografis daerah pedalaman di Batheanokay dan Pagarruyung dekat cengan jalan air yang lain, yaitu sungai Kampas kuri dan Sungai Indragin. Jika dibandingkan dengan Sungai Brangheri, muara kedua sungai ini lebih dekat dengan selat Malaka. Emas dan daerah pedalaman kemudian dipasarkan ke luar Malayu melalui sungai

\section{Eksploitasi Emas}

Nama asli Pulau Sumatra, sebagaımana ditemukan dalam ceritera rakyat atau sumber-sumber sejarah, adalah "Pulau Emas". Sejak jaman purba Pulau Sumatra terkenal dengan tambang emasnya. Istilah Pulau Ame terdapat dalam Kaba Cindue Mato dari Minangkabau. Dalam ceritera rakyat Lampung tercantum nama tanoh emas tsing, seorang pendeta Buddha dari Cina, menyebutkan Chin-chou (=negeri emas). Benta-berita Arab menyebut derigan nama sarandib, yaitu transliterasi dari nama sanskerta, Swamnadwpa,

ramtan pengan myo it malayu. Harapan penguasa Majapari dengan menempotkan Adityawamion of Matane acabo epaya Malayu dapat menginut Majapahit, sepert yang tercantum calom Kitab Nagarakertagama XIIl:1. "Terperinci puleu regara bawahan, palling deftu M"kayu.Jambr. Pakembang. Toba dan Onarmasraya " (Stamemprara 1979: 279). Namn usah Mapary krang Derrosil. tertuto dengan acanya Prasasti Amograposa dari brum 1374 di mano datam prasast itu drsetutkan beinwa Aditya. wantan adatah secrang maharajadhiraja. Dengen adanya prasast im. voak riengon Malayu merupakan negora bawahan Majapatit sepert yar.g dituns Nagarakeragama 
artinya "pulau emas". Nama lain untuk Swarnnadwipa adalah swarnna-bhumi (=tanah emas) Dalam berbagai prasasti, Pulau Sumatra dikenal dengan nama swarnnadwipa atau swarnnabhumi

Menurut Joao de Barros (1496-1570) dalam Luisaden, Camoes menggunakan nama Sumatra untuk Pulau Sumatra. Diperkirakan bahwa untuk pulau itu terdapat gunung ofir yang memungkinkan Raja Sulaiman membangun istana, kuil serta berbagal bangunan lainnya. la menyebutkan pula pada tahun 1520 dan 1521 sebuah ekspedisi dikirım ke Sumatra untuk mencari emas di Ofir. Ofir diduga merupakan nama sebuah gunung. Pada umumnya, kegiatan penambangan emas masa lampau dilakukan baik di daerah endapan aluvium maupun endapan sungai yang mengandung bıjih emas Emas demikian bersifat sekunder dengan istilah plaser. Emas sekunder itu berasal dari batuan yang ditemukan di daerah dataran tınggi (pegunungan) Emas sekunder ini kemudian dipengaruhı oleh proses pelapukan serta pengikısan Hasil kedua proses itu kemudian dihanyutkan air ke tempat yang lebih rendah. Di tempat yang rendah ini kemudian terkumpul di suatu dataran. Tempat inilah terdapat konsentrasi emas yang dapat ditambang secara sederhana.

Manuel Godinho de Ereda, seorang pengelana Portugis yang berkunjung ke Sumatra pada tahun 1807, melaporkan kegiatan pendulangan emas Setıap pagı sekelompok penduduk dari kerajaan Kampar masıng-masing membawa ayakan halus untuk mengayak pasir dari Sungai Sunetrat (Sungai Dareh) Dengan cara ini butiran emas sebesar biji-bijian atau seukuran sisik ikan dapat tertınggal dalam ayakan itu. Butiran yang lebih besar didapat dari tanah yang berasal dari sumur galian di tepı sungar Tanah galian ini kemudian dijemur di tepi sungai hingga kering. Panas mataharı menjadikan bongkahan tanah itu menjadı pecah dan hancur. Dari tanah yang hancur itu kemudian tampak butiran emas. Segenggam tanah kering dapat diremas dengan tangan secara mudah dan butiran emas dapat diambil.

Di daerah tepian Sungai Batanghari, penduduk mencari emas sekunder dengan cara menyiram-nyıram tepian sungaı dengan air. Siraman air digunakan untuk menyingkirkan tanah atau pasir yang ada di permukaan. Apabila tanah di tepi sungai mengandung emas, setelah permukaannya tersingkir akan tampak butiran emas sebesar biji Jawawut atau kacang hijau.

William Marsden, seorang pengelana berkebangsaan Inggris yang bertandang ke Sumatra pada tahun 1771-1779, memberikan laporan tentang kegiatan penambangan emas di daerah Minangkabau. Berdasarkan tempat asalnya, bijih emas dibagi menjadi dua kelompok, yaitu emas sepayang atau emas primer dan emas sungei abu atau emas sekunder Menurut taksiran, pada sekitar tahun 1700 di Minangkabau terdapat lebih dari 1200 lokası penambangan emas. Peralatan yang dipakai untuk kegiatan itu antara laın besı pengungkit (linggis), sekop palu besi besar untuk menghancurkan batuan yang mengandung bijih emas, lumpang batu, dan wadah untuk tempat mengumpulkan hancuran batuan yang me. ngandung bijih emas. Wadah ini bentuknya seperti perahu dengan ujungnya ditarik keluar darı terowongan tambang ke suatu tempat yang berair. Air dipakai untuk memisahkan butiran emas dari batuan kuarsa pengandungnya yang telah ditumbuk halus.

Daerah penghasil emas dl wilayah Kabu. paten Tanah Datar ada di sekitar lembah Sungaı Selo, Sungai Sinamar, dan Sungai Sumpur Darı tempat-tempat ini emas ditambang dan diendang untuk kemudian dipasarkan melalui dua jalan yang cukup sulit untuk masa itu Daerah pemasaran emas ada di wilayah pantai barat dan pantai timur pulau Sumatra.

Daerah lain, dı hulu Batangharı, yang merupakan tempat penghasil emas adalah di suatu tempat yang dikenal dengan nama Pangkalan Jambu, berdekatan dengan kerincı dan lembah Sungai Mesuji, Sungai Merangin, Batangasai. Seri Limun yang kaya dengan endapan emas D, daerah ini masyarakat mendulang emas pada musim kering. Kegiatan ini sudah berlangsung sejak lama.

Gambaran yang diperoleh darı pengelanapengelana asing menunjukkan masyarakat di Sumatra sejak jaman purba telah melakukan penambangan emas. Emas yang dikumpulkan berupa emas primer maupun emas sekunder. tergantung dari tempat di mana mereka mencarinya Christine Dobbin mengemukakan daerah pusat Minangkabau selama beberapa abad telah memegang peranan penting dalam perekonomian di wilayah sebelah barat Nusantara (Dobbin 1986, terjemahan) Daerah Tanah Datar merupakan penghasil salah satu dari sumber utama kegiatan perekonomian. Dari daerah ini banyak $d$ hasilkan emas. Menurut Tome' Pires di pantai barat Sumatra, bahan eksport selaın lada adalah emas, kelambak, kapur barus, kemenyan, damar madu, dan bahan makanan (Poesponegoro (3) 1984:147-148). Eksport ini ditujukan ke Malaka, tetapi kapal-kapal Gujarat juga datang ke sinı untuk membawanya langsung ke negerinya

Emas merupakan hasil tambang dari Sumatra yang penting dan utama. Oleh sebab itu. untuk menelusuri kelahiran bandar-bandar utama di Sumatra dan sistem perdagangan pada masa lampau, kita harus dapat memahami tentang peranan emas dari Sumatra. Logam ini telah ditambang di Sumatra sejak jaman sebelum kedatangan bangsa barat (Eropa) ke Asia Tenggara Demikian pentingnya emas dari Minangkabau. 
Wheatly menunjukkan bukti Kesultanan Malaka telah menantang Deli, Rokan, Siak, Kampar, dan Indragiri untuk memastikan ia dapat menjamin keamanan perdagangan emas dari kawasan pedalaman Minangkabau (Whea甘y, 1961: 309).

Penambangan emas secara besar-besaran dl mlayah Sumatra Barat baru dilakukan pada masa penjajahan. Meskipun demikian, daerah ini sudah lama dikenal sebagai penghasil emas yang utama. Penguasaan atas tambang-tambang emas dilakukan oleh para penguasa untuk tujuan politik. Emas dari daerah pedalaman Minangkabau dipasarkan ke luar Sumatra melalui pantai barat dan pantai timur Sumatra melalui jalan sungai dan jalan darat Itulah sebabnya Malayu pada masa Adityawarman mencapai kejayaannya. Pendahulu Adityowarman telah memindahkan keratonnya ke daerah pedalaman agar memudahkan pengontrolan tambang-tambang emas Daerah podalaman (sokitas Pagarruyung) dokat jalan keluar menuju Selat Malaka melalui Sungai Kampar Kiri dan Sungai Indragiri. Menuju pantal barat melalui celah Pegunungan Bukit Barisan menuju Padang. Menuju ke arah utara, melalui Muara Sipongi (juga merupakan tambang emas) menuju ke arah Tapanuli Selatan.

\section{Penutup}

Kerajaan Malayu yang lokasi geografisnya di daerah lembah Batanghari, sekurang-kurangnya telah mengalamı tiga kali pemindahan ibukota. Ibukota pertama (awal) berlokasi di daerah hilir Batangharı, di suatu tempat yang kemungkinan di Muara Jambi (de Casparis 1992) atau di Kota Jambi sekarang (Bambang Budi Utomo 1992). lbukota yang kedua berlokasi di sekitar daerah hulu Batanghari. Pemindahan kedua kemungkinan berlangsung sebelum tahun 1286 (Prasast Dharmmasraya). Ibukota terakhir (?) berlokasi di daerah Pagarruyung, dan oleh Adityawarman ibukota ditetapkan di Surawasa. Pemindahan ke daerah ini terjadi tahun $1316 \mathrm{M}$ pada masa pemerintahan Akarendrawarman (deCasparis 1992) De Casparis mengajukan alasan pemindahan ibukota karena ancaman agama baru yang berkembang di Aceh, yaitu agama isłam dari Kesultanan Samudra Pasal. karena itulah Adityawarman membuat arca bhairawa dan menetapkan Surawasa sebagal pusat pemerintahan. Adityawarman beranggapan agama Islam tIdak hanya mengancam agama Buddha yang dipeluknya, melainkan juga membahayakan tahta raja.

Dugaan yang diajukan de Casparis dapat diterıma, tetapı dapat ditambahkan bahwa Adityawarman juga bemiat menguasal tambang emas yang banyak terdapat di wilayah Minangkabau. Selaın itu, Jika pusat pemerintahan ada di caerah Surawasa, akses menuju Selat Malaka yang merupakan jalur lalulintas perekonomian akan lebih dekat lagi, yaitu melaluı Sungaı Kampar Kiri dan Sungai Indragiri. Demikian juga akses menuju pantai barat Sumatra tempat para pedagang dari India dan Arab biasa berlabuh mengambil barang komoditi. Bukti prasasti dari pantai barat Sumatra menunjukkan adanya komunitas para pedagang Tamil di pantai barat Sumatra.

Setelah Malayu di bawah Adityawarman mencapai kejayaannya, tibalah masa yang gelap bagi Malayu. Berita mengenal Malayu sebagaı kerajaan yang bercorak Buddha todak pemah terdengar lagi. Namun demikian perdagangan emas dari daerah Minangkabau masih tetap berianjut melalui jalur sungai Kampar Kuri dan Indragiri.

\section{KEPUSTAKAAN}

Bambang Budi Utomo,1990, Teori Garis Pantar Sumalera Timur:Pengaruhnya Tentadap $P_{e}$ nempatan Pusat Sriwijaya, Monumen:143. 155. Depok: Lembaran Sastra FS-UI

,1992, Batanghan Riwayatmu Dulu, makalah dalam Seminar Sejarah Malayu Kuno 157-92. Jambi:Pemda Tk. I ProunsI Jambi dan Kantor Wilayah Depdikbud Jambı.

Boechori,1979, An Old Malay Inscription of Srivijaya at Palas Pasemah (South Lampung) dalam Pra Seminar Penelitian Sriwijaya 18-40. Jakarta:Puslit Arkenas.

--,1984, Laporan Hasil Penelitian Lempe ngantempengan Emas dari Candi Gumpung (Naskah, tidak diterbitkan).

Dobbin, Christine, 1977,Economic Change in Mrnangkabau as a Factor in the Rise of the Padri Movement 1784-1830, dalam Indonesia 23: $1-38$.

1986, Perkembangan dan Perubahan dalam Jaringan Perdagangan Luar Negerr (terjemahan dan Islamic Revivalism in a Changing Peasant Economy oleh Juwono Sudibjo) Padang:Museum Negeri Adityawarman

S Di Labo Tua ditertedon inskorps berbohasa Tamil yang berangka tatur) 1088 (Sasti, 1932:314-327). isinya menyeduran lentang persenkatan dagong Tamil yang terdiri atas 1500 orang. Labo Tua adaton setuah kampung yang letakna di sebelah omur Barus di pantai barat Sumatra 
Groencreldt,W P 1960, Historical Notes on Indonesia and Malaya, Compiled from Chinese Sources. Djakarta: Bhratara

Hasan Djafar, 1992,Prasastı-prasastı Masa Kerajaan Malayu Kuno dan Beberapa Permasalahannya riakalah dalam Seminar Sejarah Malayu Kuno 49-80 Jambi:Pemda Tk I Jam. bı dan Kantor Depdikbud Jambı

Hirth.F \& W.W Rockhill, 1911,Chau-ju-kua: His Work on the Chinese and Arab Trade in the Twelfth and Thirteenth Centuries, entitled Chu-fan-chi St Petersburg: Imperial Academy of Science

irfan Nia Kurnıa Sholihat, 1983, Kerajaan Sriwijaya. Bandung: Girimuktı Pasaka.

Kempers, A J Bernet, 1959 Ancient indonesia An Massachustts. Harvard University Press

Kern H 1916-1917. Inscripties van de Indische Archipel dalam VG 6 dan 7 s'Gravenhage Martinus Nijhoff

Krom. N J 1912. Inventaries der Oudheden in de Padangsche Bovenlanden, dalam OV 1912 Bıllage G.H 33-52

Marsden.William 1966, History of Sumatra Kuala Lumpur: Oxford University Press

Mckinnon. E Euwards, 1992, Malayu Jambı Interiocal and international Trade 111th to 13th Centuries). Seminar Sejarah Malayu Kuno Jambi Pemda Tk I Jamb dan Kantor Wi. Iayah Depdikbud Jambı

Moens J L , 1924, Het Buddhisme op Java en Sumatra in zijn laatste bloeiperiode, dalam TBG 64: $521-80$

1937 Crivijaya Yava en Kataha, dalam TBG 77 : $317 \cdot 487$

Pelliot. Paul,1904,Deux Itiberarres de Chine en inde a la Fin du VIlle Siecle, salam BEFEO tome IV.

Pitono Hardjowardojo,R 1965,Pararaton Djakarta Bhratara

Poesponegoro,Marwati Djoenet \& Nugroho Notosusanto, 1984, Sejarah Nasional Indonesia II Jakarta P.N Balai Pustaka.
Slametmulyana, 1979, Nagarakretagama dan Tafsir Sejarahnya. Jakarta: Bhratara.

1981, Kuntala, Sriwijaya dan Suwarnabhumi Jakarta: Yayasan Idayu

Suleiman, Satyowatı.1981.Sculptures of Ancient Sumatra. Jakarta:Proyek Penelitian Purba. kaia Jakaita

Wheatly, Paul, 1961 The Golden Chersonese Kuala Lumpur University of Malaya Wolters. OW

1970, The Fall of Srivijaya in Malay His. tory Kuala Lumpur: Oxford University Press 